\title{
HTM 01-05: eating the elephant a bite at a time
}

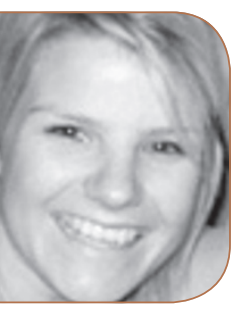

\section{'Start with why'}

If managed efficiently, being nominated your practice's decontamination lead can be an empowering opportunity for you and your team. Emma Male' explores a practical, step by step approach to applying HTM 01-05 to your practice.

\section{Eating the proverbial elephant}

When I was asked by my employer in 2009 to convert 86 pages of a new decontamination guidance document into an efficiently functioning decontamination system for our busy, five-surgery dental practice, it felt like I had been asked to split an atom while summiting the north face of the Eiger. I could not envisage me, a newly promoted Clinical Manager with a purely dental nursing background, steering our practice ship through the seas of decontamination compliance. However, with a deep breath, a positive approach and with a practice principal who believed in me, I made a plan and broke down what seemed like a mammoth task into small manageable chunks.

\footnotetext{
' Emma is Practice Manager at Martock Dental Practice and director at Elite Dental Nursing Ltd. She has worked in dentistry since 2003 and during that time has worked as an orthodontic nurse, dental implant nurse, practice manager, a dental nurse tutor on the National Diploma in Dental Nursing as well as providing in-house dental implant nurse and CPD training.
}

To quote leadership expert Simon Sinek, I needed to 'start with why' (https://www. startwithwhy.com/). Sinek believes that when you know why you are doing something, you then know the underlying value of doing it, thus you are more likely to complete the task well. If I was to get compliance from our team in operating new decontamination procedures then I needed to fully understand the 'the why' of HTM 01-05 guidance and importantly, ensure our team did too.

\section{Why is HTM 01-05}

guidance important?

- HTM 01-05 is a document designed to be used as guidance for decontamination in dental practice first published by the Department of Health in 2009 and updated in $2013^{1}$

- Its aim is to improve the standard of decontamination in primary care dental services by giving guidance on decontaminating reusable instruments and related measures taken to reduce cross infection, thus protecting patients and staff

- By adhering to the guidance, healthcare providers are complying with the Health and Social Care Act 2012 which they are legally and morally obliged to do. ${ }^{2}$

\section{Team responsibility}

and accountability

Effective infection prevention control and compliance is achieved by ensuring that all team members who are involved in clinical and decontamination procedures and all management staff are adequately trained and knowledgeable of their roles and responsibilities.

All staff registered with the General Dental Council (GDC) must adhere to the GDC's Standards for the dental team. ${ }^{3}$ It is each staff member's responsibility to complete verifiable continual professional development (CPD) in areas including cross infection control. It is also their responsibility to ensure they have received the mandatory and recommended vaccinations required to safely work in a clinical environment and to ensure anything which may affect their fitness to practise is declared and reviewed in the appropriate manner.

The GDC's standards relevant to infection prevention control are:

Standard 1 Put patients' interests first Standard 6 Work with colleagues in a way that is in patients' best interests

Standard 7 Maintain, develop and work within your professional knowledge and skills Standard 8 Raise concerns if patients are at risk. 
Clear job descriptions documenting infection control roles and responsibilities can also ensure accountability of staff members carrying out decontamination.

\section{How does HTM 01-05 fulfil \\ its purpose?}

The HTM 01-05 guidance document ensures compliance in decontamination in primary care dental practice by:

- Providing accessible online reference

- Ensuring practices have local policy in each area of cross infection control

- Ensuring regular auditing is carried out of all cross infection control procedures

- Ensuring practices have a local policy in place for each aspect of infection prevention

- Ensuring regular cross infection control training is undertaken by staff

- Setting two levels of compliance: Essential Quality and Best Practice

- Ensuring practices have a team member accountable for all decontamination procedures.

The guidance document is broken down into three sections:

1. Decontamination policy and foreword

2. Advice to dentists and practice staff (local decontamination)

3. Engineering, technology and standards.

\section{Auditing}

As well as providing primary care service with guidance HTM 01-05 stipulates that an audit of compliance must be carried out every six months. The Infection Prevention Society has a free downloadable audit tool available for use by all practices at the following link: http://www.ips.uk.net/professional-practice/ resources $1 /$ dental-audit-tool/ ${ }^{4}$
- Legionella risk management.

\section{Local policy and staff training}

The guidance document and audit tool will ensure that dental practices have a written local policy in each of the above infection prevention measures and that staff training is carried out at appropriate intervals (usually annually).

\section{'HAVING A DECONTAMINATION LEAD GIVES A TEAM}

\section{MEMBER ACCOUNTABILITY AND AUTHORITY TO}

\section{GAIN AND IMPART KNOWLEDGE...}

When auditing compliance the decontamination lead in your practice or another trained staff member will check and initiate compliance in the following areas:

- Prevention of blood borne virus exposure

- Decontamination, environmental design and cleaning

- Hand hygiene

- Management of dental medical

- Personal protective equipment (PPE)

- Waste management and disposal
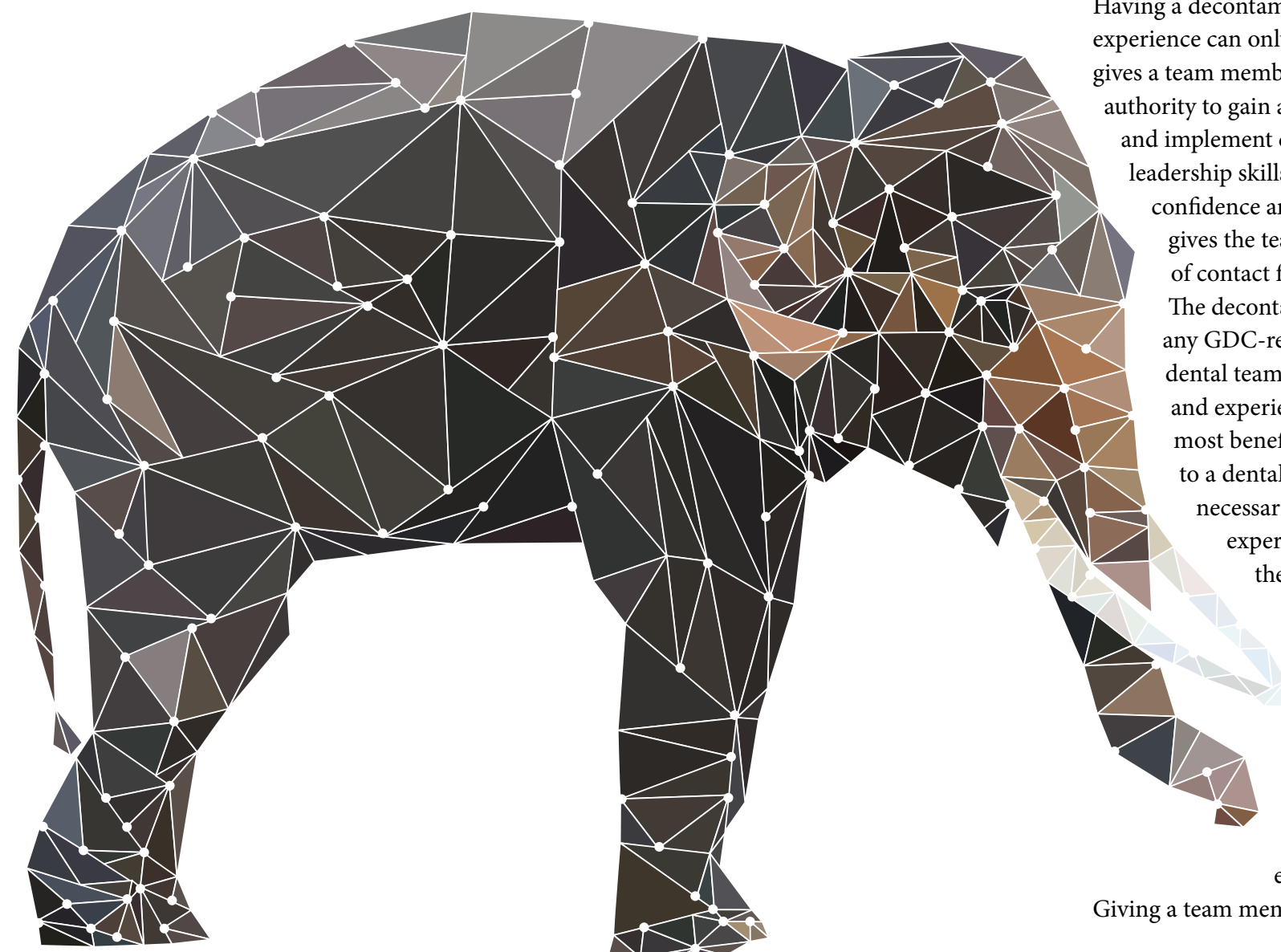

Essential quality and best practice The HTM 01-05 guidance document sets out two benchmarks of infection prevention compliance: Best Practice and Essential Quality. All dental practices have a legal obligation and moral duty to meet the Essential Quality standard in decontamination procedures. However, practices should have a plan in place showing that they are working towards best practice.

\section{Decontamination lead}

Having a decontamination lead in my experience can only be a positive thing. It gives a team member accountability and to gain and impart knowledge nd implement communication and adership skills which can encourage confidence and career progression. It gives the team a knowledgeable point of contact for cross infection control. The decontamination lead can be -registered member of the ental team though in my opinion nd experience I have found it the ost beneficial to allocate the role a dental nurse. This does not essarily have to be the most exerienced dental nurse in the practice but someone who is solution focused, a good communicator and would thrive on the challenge and take pride in making sure that the practice team and procedures are efficient, effective and compliant.

Giving a team member the responsibility 
can be a fantastic opportunity to allow them to demonstrate their potential and credibility and lead onto gaining other areas of responsibility.

\section{Steps to compliance}

\section{7) Familiarise yourself}

Set aside some time ideally in a quiet office or surgery to familiarise yourself with the document. The document can seem daunting at first due to its size, however, once you get to know where to find information, the document becomes a valuable, easy to use tool.

\section{2) Download the audit tool}

Locate the Infection Prevention Society's audit tool which you can either download as a PDF version or download a program to your computer's desk top. ${ }^{4}$ which you are auditing, you will need to write a local policy. I find the easiest way to make sure I include everything into the local policy is to work through the audit and include all of the items which are appropriate to the policy. It is good practice to go through the policies at your team meetings to ensure the team know their roles and responsibilities, with them signing the policy to confirm this.

\section{6) Ongoing audit and review}

After six months of your initial audit you will need to re-audit and document any changes. Each policy should be reviewed and updated every 12 months or with any changes incurred before the annual review.

1. Department of Health. Decontamination. Health Technical Memorandum 01-

05: Decontamination in primary care

\section{'IT IS GOOD PRACTICE TO GO THROUGH THE}

\section{POLICIES AT YOUR TEAM MEETINGS TO}

\section{ENSURE THE TEAM KNOW THEIR}

\section{ROLES AND RESPONSIBILITIES...'}

\section{3) Auditing}

One section at a time, work though the audit tool to see if you are already compliant. Highlight actions to take should any areas need any attention.

\section{4) Implementing changes}

If there are non-compliant areas which are shown on the section of audit you are undertaking, you can immediately take action straight away if it is a simple task like booking a professional to come and carry out a Legionella risk assessment, for example. If it involves the way other team members work then you will need to consult, explain and possibly train them in any implemented changes in order to make sure that they understand how and why that particular action needs to be undertaken. Some actions may take a while; if this happens mark the action point on your audit point as pending and mark (if necessary) that you are currently non-compliant until you can take action.

\section{5) Local practice policy}

Once you have taken action to ensure you are compliant in the area of infection prevention dental practices. 2013 edition. Available at: https://www.gov.uk/government/ uploads/system/uploads/attachment_data/ file/170689/HTM_01-05_2013.pdf (accessed April 2016).

2. legislation.gov.uk. Health and Social Care Act 2012. Available at: http://www. legislation.gov.uk/ukpga/2012/7/contents (accessed April 2016).

3. General Dental Council. Standards for the dental team. 30 September 2013. Available at: http://www.gdc-uk. org/Dentalprofessionals/Standards/ Documents/Standards\%20for\%20the\%20 Dental\%20Team.pdf (accessed April 2016).

4. Infection Prevention Society. Dental Audit Tool. V2 released June 2013. Available at: http://www.ips.uk.net/professionalpractice/resources1/dental-audit-tool/ (accessed April 2016).

This is Emma Male's first article for BDJ Team and we look forward to running further features from her in future issues.
Key points

1. See the role of decontamination lead as an opportunity to develop yourself and career and include it on your CV

2. Be wary of companies who claim that their products will make your practice compliant; they want to sell their product rather than make your practice compliant. Always refer back to the official HTM 01-05 document if you are in any doubt

\section{Always keep your manufacturers'} instructions. They hold important information about the most effective way of decontaminating and maintaining your instruments and equipment.

4. Not all team members will want to change the way they work. That's normal.

- Listen carefully to any team members who are struggling to adapt to change.

- Reassure them by asking which aspects they are finding challenging

- Explain why the changes are important along with benefits of any new systems

- Ask them for their input in providing a solution which would be better suited to them and the team. Even if they cannot provide a solution, they will feel they have been listened to and will comply with the procedures you have put in place.

\section{Don't be confused by unreliable} information. In the age of social media, blogging and internet forums we are bombarded with information on a daily basis about compliance but not all of it is credible. If a practice manager in the next town keeps her patient records in an underground bunker 25 miles away from the practice because she believes that's the only way of truly being compliant with The Data Protection Act, it does not mean that this is the new national procedure we must all adapt. Take other people's interpretation of guidance lightly and always go to the correct authorities for information. 